\title{
Pt-MoSx/Graphene Nanocomposite for the Hydrogen Evolution Reaction
}

\author{
Shu Huei HSIEH ${ }^{1}$, Li-Lun $\mathrm{CHANG}^{2}$, WenJauh $\mathrm{CHEN}^{2, *}$
}

\author{
${ }^{1}$ Department of Materials Science and Engineering, National Formosa University. 64, Wunhua \\ Road, Huwei, Yunlin, Taiwan, 632
}

${ }^{2}$ Graduate School of Materials Science, National Yunlin University of Science and Technology, 123 University Road, Section 3, Douliou, Yunlin, Taiwan, 64002

\begin{abstract}
Keywords:Pt, Molybdenum disulfide, Graphene, Hydrothermal synthesis, Hydrogen evolution Abstract.In this study, a catalyst was fabricated based on $\mathrm{Pt}$ nanoparticles on $\mathrm{MoS}_{2} /$ graphene $\left(\mathrm{MoS}_{2} / \mathrm{GN}\right)$. The Pt-MoS $/ \mathrm{GN}$ was formed from graphite by modified Hummers and Offeman's method, hydrothermal method and polyol synthesis method. The graphene oxide (GO) sheets were synthesized by modified Hummers and Offeman's method. The graphene is to obtain by reduction of GO films by sodium tetrahydridoborate. Then, the graphene deposited with Pt particles were put in ethylene glycol for a reflux at $150{ }^{\circ} \mathrm{C}$ for 6 hours. Obtained Pt-MoS 2 /graphenecatalysts were characterized by X-ray diffraction analysis (XRD), scanning electron microscopy (SEM), and and energy dispersive spectroscopy (EDS). Cyclic voltammetry (CV) was utilized to estimate the electrochemical performance of the $\mathrm{Pt}-\mathrm{MoS}_{2} / \mathrm{GN}$ nanocomposites. The results show that the Pt-MoS $2 /$ GNnanocomposites modified glasscarbonelectrode (GCE) shows a high sensitivity and low detection limit for hydrogen peroxide and glucose detection. The activity of Pt- $\mathrm{MoS}_{2} / \mathrm{GN}$ nanocomposites can be enhanced after adding the $30 \mathrm{wt} \% \mathrm{MoS}_{2}$. The Pt-MoS $/ \mathrm{GN}$ shows the highest current value reached $-25 \mathrm{~mA}$ at $-0.2 \mathrm{~V}$, which is higher than that of pure Pt/GN. The Pt-MoS $/ 2 \mathrm{GN}$ nanocomposites also exhibit superior electrochemically active surface area (ECSA). The work may provide more insight into synthesizing hybrid photocatalytic materials with high activities for applications in solar energy conversion and utilization.
\end{abstract}

\section{Introduction}

Hydrogen is an ideal clean and renewable energy carriertoreplace fossil fuels in the future.Splitting water offers onesimple way to produce hydrogen. However, efficient hydrogen generation requiresadvanced electrocatalysts [1,2].The best hydrogen evolution reaction (HER)catalysts consist of Pt or Pt-based materials withnegligible overpotentials [2]. But theyare too expensive to be widely used. Replacementof Pt with earth-abundanceelements would be desirable tofacilitate the global scalability of such potential clean-energytechnologies.

Recently nanometer-scale molybdenum disulfide $\left(\mathrm{MoS}_{2}\right)$ with exposed edges has been identified as a promising electrocatalystfor the HER due to its low cost, high chemicalstability and excellent electrocatalytic properties [3].Molybdenum disulfide, a two-dimensional transition metal disulfide (TMD) has a layered structure comprising S-Mo-S layers plus the weak Van de Waal force interactions, nanoparticles/flake edge area of a large number of catalytic and there is a high active sites more suitable semiconductor material. Of about $1.2 \mathrm{eV}$ when molybdenum disulfide structure form below to block material indirect bandgap, but a single form of molybdenum disulfide is a direct band gap of about $1.8 \mathrm{eV}$ (similar to 2D graphene structure).(2-D) graphene has emerged as high potential material and increasingly attracted attention owing to its specific properties, including excellent electron mobility, large specific surface area, flexible structure, high transparency and stability at room temperature [4-7]. The integration of graphene, $\mathrm{MoS}_{2}$ and nanoparticles (NPs) has been actively explored for applications in many areas. Loading of nanoparticles on highly conductive graphene nanosheets gives rise to hybrid nanocomposites. The hybrid nanomaterials could provide larger electrochemically active surface areas for the adsorption of biomolecules and effectively accelerate the electron transfer between electrode, making the hybrid nanocomposites ideal materials for high-performance electrocatalyst for the hydrogen evolution reaction.In this work, the $\mathrm{Pt}-\mathrm{MoS}_{2} / \mathrm{GN}$ was formed from graphite by modified Hummers and Offeman's method,hydrothermalsynthesis, and polyol synthesis method. The results show that 


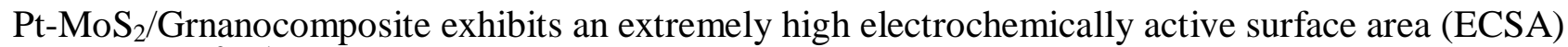
value $\left(350 \mathrm{~m}^{2} \mathrm{~g}^{-1}\right)$. The Pt-MoS $/ \mathrm{GN}$ shows the highest current value reached $-25 \mathrm{~mA}$ at $-0.2 \mathrm{~V}$, which is higher than that of pure $\mathrm{Pt} / \mathrm{GN}$.

\section{Experimental}

In this work, the graphene oxide (GO) sheets were synthesized by modified Hummers and Offeman's method. Through this process, the natural graphite powder was exfoliated by strong oxidizing agent $\left(\mathrm{KMnO}_{4}+\mathrm{H}_{2} \mathrm{O}_{2}\right)$. The graphene is to obtain by reduction of $\mathrm{GO}$ films by sodium tetrahydridoborate. $\mathrm{MoS}_{2} / \mathrm{GNnanocomposites}$ were prepared hydrothermal method. $20 \mathrm{mg}$ of graphene oxide, various amounts $(5-30 \mathrm{mg})$ of sodium molybdate $\left(\mathrm{Na}_{2} \mathrm{MoO}_{4} 2 \mathrm{H}_{2} \mathrm{O}\right)$, various amounts (10-60 mg)thiosulfate acetamideand $60 \mathrm{~mL}$ of distilled water were added into a Teflon-lined stainless steel autoclave with a capacity of $100 \mathrm{~mL}$. The autoclave was sealed, maintained at $200{ }^{\circ} \mathrm{C}$ for $24 \mathrm{~h}$ and cooled to room temperature naturally. The product was filtered off, washed with distilled water and ethanol several times, and dried in a vacuum at $50{ }^{\circ} \mathrm{C}$ for 24 hours. The Pt-MoS $/ \mathrm{GN}_{2}$ was manufactured as follows: $\mathrm{MoS}_{2} / \mathrm{GN}(50 \mathrm{mg}$ ) was dispersed in $100 \mathrm{~mL}$ of ethylene glycol by ultrasonic treatment $30 \mathrm{~min}$. Then $100 \mathrm{mg}$ of $\mathrm{H}_{2} \mathrm{PtCl}_{6} \cdot 6 \mathrm{H}_{2} \mathrm{O}$ were added to $100 \mathrm{~mL}$ of the as-obtained $\mathrm{MoS}_{2} / \mathrm{GNs}$ dispersion with magnetic stirring for $30 \mathrm{~min}$. And the $\mathrm{pH}$ value of this mixture was adjusted to 3 using $\mathrm{HCl}$. Finally the solution reflux at $150^{\circ} \mathrm{C}$ for 3 hours. After rinsing and filtrating, the Pt-MoS $/ \mathrm{MN}_{2}$ was dried at $70{ }^{\circ} \mathrm{C}$ for 12 hours.

The Pt-MoS $/$ /GN was characterized by X-ray diffraction, scanning electron microscopy (SEM), and energy dispersive spectroscopy (EDS). Powder X-ray diffraction (XRD) analyzes was performed on a Bruker D8 Advance diffractometer with $\mathrm{Cu} \mathrm{K}_{\alpha}$ radiation. A scanning transmission electron microscope (SEM, JEOL JSM-6510LV) were used for the observation of microstructure of the $\mathrm{Pt}-\mathrm{MoS}_{2} / \mathrm{GN}$ nanocomposites. Cyclic voltammetry (CV) was utilized to estimate the electrochemical performance of the $\mathrm{Pt}-\mathrm{MoS}_{2} / \mathrm{GN}$ nanocomposites. The cyclic voltammetric $(\mathrm{CV})$ was performed at a standard three-electrode electrochemical cell with Jiehan (make in Taiwan) electrochemical working station. CV measurements were performed in $0.1 \mathrm{M}$ Phosphate buffered solutions (PBS) (pH 7.0) solutions with a scan rate of $20 \mathrm{mV} / \mathrm{s}$. PBS were prepared using $0.1 \mathrm{M} \mathrm{Na}_{2} \mathrm{HPO}_{4}$ and $0.1 \mathrm{M}$ $\mathrm{KH}_{2} \mathrm{PO}_{4} \cdot \mathrm{Pt}-\mathrm{MoS}_{2} / \mathrm{GN}$ electrode was made by affixing the membrane to a glassy carbon electrode (3 $\mathrm{mm}$ in diameter, GCE) and used as the working electrode. A saturated calomel electrode (SCE, $\mathrm{Hg} / \mathrm{Hg}_{2} \mathrm{Cl}_{2}$ (sat. $\mathrm{KCl}$ )) was used as the reference and a platinum plate was used as the counter electrode. Prior to modification, GCE was polished with $1.0 \mu \mathrm{m}, 0.3 \mu \mathrm{m}$ and $0.05 \mu \mathrm{m}$ alumina powders in sequence, rinsed thoroughly with DI water between each polishing step, sonicated in ethanol and DI water for 10 min respectively. Pt-MoS $/ \mathrm{GN}$ was dispersed in DI water with ultrasonication to achieve a $0.5 \mathrm{mg} / \mathrm{mL}$ concentration. Then $5 \mu \mathrm{L}$ of the above solution was carefully pipetted onto the GC electrode surface. The coatings were dried at room temperature for $1 \mathrm{~h}$.

\section{Results and discussion}

Fig. 1 (a)-(d) shows the XRD pattern of the graphite oxide (GO), graphene, $\mathrm{MoS}_{2} / \mathrm{GN}$, and Pt-MoS $/ \mathrm{GN}_{2}$ nanocomposites, respectively. As observed in Figure 2(a), the characteristic peak of GO (002) is located at a $2 \theta$ angle of $11.3^{\circ}$, and the spacing between layers is $0.83 \mathrm{~nm}$. Figure 2(b) presents the XRD spectrum of graphene, which was reduced from GO by sodium borohydride $\left(\mathrm{NaBH}_{4}\right)$. Due to the relatively small number of graphite layers in the graphene film, the diffraction intensity of the graphene film is broaden, the diffraction peak of graphene at $26.5^{\circ}$. Fig. 2 (c) shows the XRD patterns of $\mathrm{MoS}_{2} /$ graphene. The diffraction peak angles are $13.5^{\circ}, 33^{\circ}, 39^{\circ}, 48.5^{\circ}, 58.7^{\circ}, 59.1^{\circ}$ and $70.9^{\circ}$, which correspond to 2H- molybdenum disulfide(002), (100), (103), (006), (105), (110), and (201), respectively. The XRD pattern of Pt-MoS $/ \mathrm{GN}$ sample shows diffraction peaks at $39.75^{\circ}, 46.23^{\circ}$, and $67.45^{\circ}$ which are in good agreement with the $\left(\begin{array}{lll}1 & 1 & 1\end{array}\right),\left(\begin{array}{lll}2 & 0 & 0\end{array}\right)$, and $\left(\begin{array}{lll}2 & 2 & 0\end{array}\right)$ crystal planes of platinum with face-centered-cubic (fcc) phase (JCPDS 65-28680). This implies the successful synthesis ofPt-MoS $/$ GN nanocomposites. 




Fig. 1 XRD pattern of the graphite oxide $(\mathrm{GO})$, graphene, $\mathrm{MoS}_{2} / \mathrm{GN}$, and $\mathrm{Pt}-\mathrm{MoS}_{2} / \mathrm{GN}$ nanocomposites, respectively.

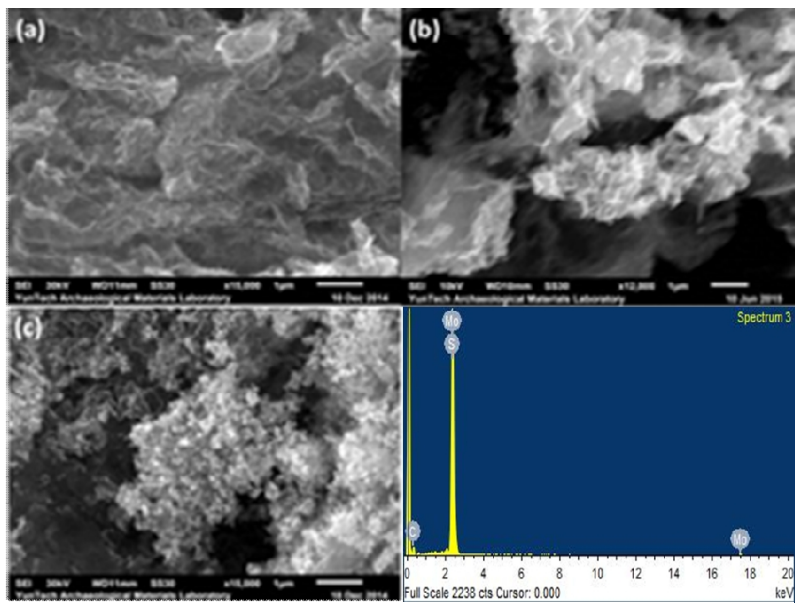

Fig. 2 (a) and (b) SEM images of $\mathrm{MoS}_{2} / \mathrm{GN}$, (c) SEM images of $\mathrm{Pt}-\mathrm{MoS}_{2} / \mathrm{GN}$, (d) EDS of $\mathrm{MoS}_{2} / \mathrm{GN}$.

Fig. 2 (a) and (b) shows the SEM image of the obtained $\mathrm{MoS}_{2} / \mathrm{GN}$.It clearly illustrates $\mathrm{MoS}_{2}$ is supported on the GN surface.Figure 2 (c) shows the SEM image ofPt-MoS $/ \mathrm{GN}_{2}$ nanocomposites. It can be found that the platinum nanoparticles well dispersive on $\mathrm{MoS}_{2} / \mathrm{GN}$.EDS was used to determine the composition of the layered $\mathrm{MoS}_{2} / \mathrm{GNnanocomposite.} \mathrm{The} \mathrm{results} \mathrm{showed} \mathrm{that} \mathrm{the} \mathrm{samples}$ containC, Mo (62.1), and S (31.35). Thecalculated atomic ratio of $S$ to Mo element was about 2, approachingthe theoretical value of $\mathrm{MoS}_{2}$. These values indicate that the productsare stoichiometric $\mathrm{MoS}_{2}$.

To study the electrocatalytic activity of the Pt-MoS $/$ GN,thePt-MoS $/$ GN was deposited on glassy carbon electrode (GCE) and evaluated in $0.5 \mathrm{M} \mathrm{H}_{2} \mathrm{SO}_{4}$ with ascan rate of $20 \mathrm{mV} / \mathrm{s}$. The Pt/GN was also tested for comparison. Figure 3 shows the polarization curves of $\mathrm{Pt}-\mathrm{MoS}_{2} / \mathrm{GNwith}$ different amounts of $\mathrm{MoS}_{2}$ and Pt/GN. The Pt-(30wt\%) $\mathrm{MoS}_{2} / \mathrm{GN}$ electrodes produced current densities of -25 $\mathrm{mA} \mathrm{cm}$ at overpotentials of $-0.2 \mathrm{~V}$. The electrocatalytic HER activity of the Pt- $(30 \mathrm{wt} \%) \mathrm{MoS}_{2} / \mathrm{GN}$ electrodes also compares to other Pt-MoS $/ \mathrm{GN}$ with with different amounts of $\mathrm{MoS}_{2}$, including Pt-(10 $\left.\mathrm{wt}^{2}\right) \mathrm{MoS}_{2} / \mathrm{GN}\left(-4.2 \mathrm{~mA} / \mathrm{cm}^{2}\right), \mathrm{Pt}-(50 \mathrm{wt} \%) \mathrm{MoS}_{2} / \mathrm{GN}\left(-13.8 \mathrm{~mA} / \mathrm{cm}^{2}\right), \mathrm{Pt}-(90 \mathrm{wt} \%) \mathrm{MoS}_{2} / \mathrm{GN}(-8.2$ $\left.\mathrm{mA} / \mathrm{cm}^{2}\right)$, and $\mathrm{Pt} / \mathrm{GN}\left(-18.9 \mathrm{~mA} / \mathrm{cm}^{2}\right)$. The cathodic current density reached $25 \mathrm{~mA} / \mathrm{cm}^{2}$ at $200 \mathrm{mV}$ over Pt-(30wt\%) $\mathrm{MoS}_{2} / \mathrm{GN}$ material, showing 6-fold, 2-fold and 4-fold enhancement with those of $\mathrm{Pt}-(\mathrm{X} w \mathrm{wt} \%) \mathrm{MoS}_{2} / \mathrm{GN}$ material with $10 \mathrm{wt} \% \mathrm{MoS}_{2}, 50 \mathrm{wt} \% \mathrm{MoS}_{2}$, and $90 \mathrm{wt} \% \mathrm{MoS}_{2}$, respectively. The HER activity of Pt-MoS $/$ GN increases first and reaches the maximum value when the $\mathrm{MoS}_{2}$ content is $30 \mathrm{wt} . \%$, then drops down afterward, which indicates that the synergistic effect is not obvious when the amount of $\mathrm{MoS}_{2}$ is low or large.Fig. 4 shows the current density variation with voltage in $\mathrm{CV}$ test for $\mathrm{Pt}-(30 \mathrm{wt} \%) \mathrm{MoS}_{2} / \mathrm{GN}$ nanocomposites sample.The ECSAs forPt-(30wt $\%) \mathrm{MoS}_{2} / \mathrm{GNelectrode}$ was estimated to be $350 \mathrm{~m}^{2} \mathrm{~g}^{-1}$. The integrated area of the hydrogen absorption and desorption peaks for $\mathrm{Pt}-(30 \mathrm{wt} \%) \mathrm{MoS}_{2} / \mathrm{GN}$ is larger than those of $\mathrm{Pt}-(\mathrm{X}$ $\mathrm{wt} \%) \mathrm{MoS}_{2} / \mathrm{GN}$ material with $10 \mathrm{wt} \% \mathrm{MoS}_{2}, 50 \mathrm{wt} \% \mathrm{MoS}_{2}$, and $90 \mathrm{wt} \% \mathrm{MoS}_{2}$ electrode, respectively. The larger ECSAs indicate that Pt- $(30 \mathrm{wt} \%) \mathrm{MoS}_{2} / \mathrm{GN}$ electrode has more active sites in the electrocatalytic process, suggesting that the $\mathrm{Pt}-\mathrm{MoS}_{2} / \mathrm{GN}$ might have great potential in practical HER application.

\section{Summary}

In this work the $\mathrm{MoS}_{2} / \mathrm{GNnanocomposites} \mathrm{were} \mathrm{prepared} \mathrm{by} \mathrm{hydrothermal} \mathrm{method.Then} \mathrm{electrode}$ catalyst Pt particles were reduced on their surface in ethylene glycol and application to hydrogen evolution reaction. The high electrochemical active surface area with $350 \mathrm{~m}^{2} / \mathrm{g}$ can be obtained in $\mathrm{Pt}-(30 \mathrm{wt} \%) \mathrm{MoS}_{2} / \mathrm{GN}$ sample. The cathodic current density reached $25 \mathrm{~mA} / \mathrm{cm}^{2}$ at $200 \mathrm{mV}$ over $\mathrm{Pt}-(30 \mathrm{wt} \%) \mathrm{MoS}_{2} / \mathrm{GN}$ material, showing 6-fold, 2-fold and 4-fold enhancement with those of Pt-(X wt $\%) \mathrm{MoS}_{2} / \mathrm{GN}$ material with $10 \mathrm{wt} \% \mathrm{MoS}_{2}, 50 \mathrm{wt} \% \mathrm{MoS}_{2}$, and $90 \mathrm{wt} \% \mathrm{MoS}_{2}$, respectively. The 
HER activity of Pt-MoS $/$ GN increases first and reaches the maximum value when the $\mathrm{MoS}_{2}$ content is $30 \mathrm{wt} . \%$, then drops down afterward, which indicates that the synergistic effect is not obvious when the amount of $\mathrm{MoS}_{2}$ is low or large.

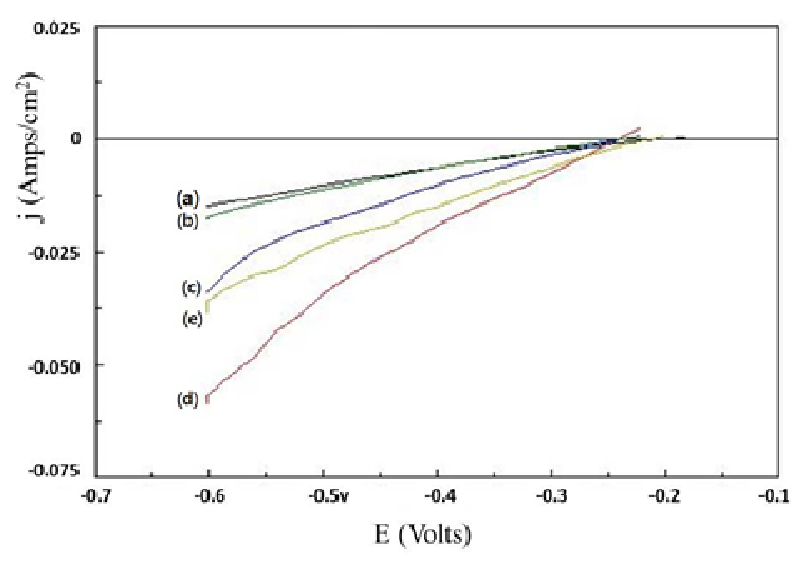

Fig. 3the polarization curves of $\mathrm{Pt}-\mathrm{MoS}_{2} / \mathrm{GN}$ with different amounts of $\mathrm{MoS}_{2}$ and Pt/GN..

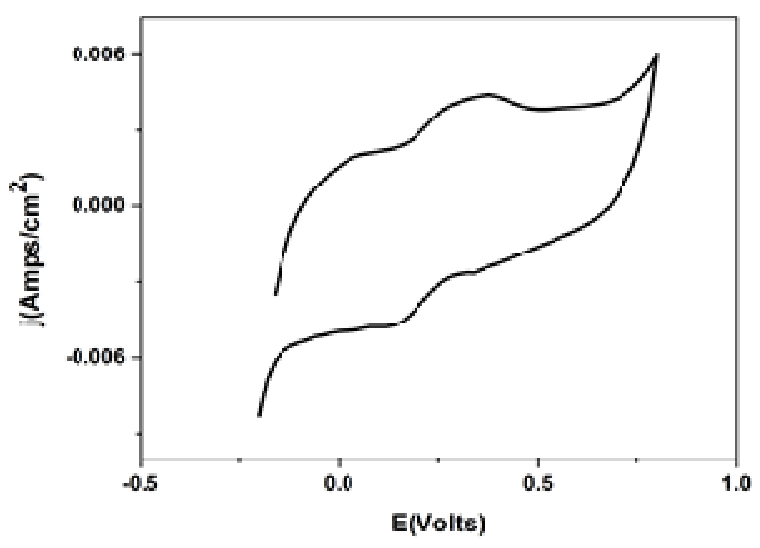

Fig. 4the current density variation with voltage in $\mathrm{CV}$ test for Pt-(30 wt\%) $\mathrm{MoS}_{2} / \mathrm{GN}$ nanocomposites sample.

\section{Acknowledgement}

The authors are grateful for the financial support by the National Science Council of the Republic of China under the contracts MOST 103-2221-E-224 -015.

\section{References}

[1] H.B. Gray, Nat. Chem. 1 (2009) 7.

[2]M.G. Walter, E.L. Warren, J.R.McKone, S.W. Boettcher, Q.Mi, E.A.Santori, N.S. Lewis, Chem. Rev. 110 (2010) 6446.

[3] Y. Yan, X.M. Ge, Z.L. Liu, J.Y. Wang, J.M. Lee, X. Wang, Nanoscale 5 (2013) 7768.

[4] A.K. Geim, K.S. Novoselov, Nature Materials.63(2007)183.

[5] J. Meyer, et al. Nature. 4467131 ( 2007) 60.

[6] K.S. Novoselov, A.K. Geim, S.V. Morozov, D. Jiang, Y. Zhang, S.V. Dubonos, I. V.

Grigorieva,A. A. Firsov,Science,306(2004) .

[7] M.D. Stoller,S. Park,Y. Zhu, J. An,R.S. Ruoff, Nano Lett., 8(2008) 3498. 